\title{
Insurance rating of patients with inflammatory bowel disease: Report of a conference on morbidity and mortality
}

\author{
IVAN T BECK MD PhD FRCPC FACP FACG, DESMOND J LEDDIN MD FRCPC, SUZANNE E LEMIRE MD FACG, \\ ELDON A SHAFFER MD FRCPC, LLOYD R SUTHERLAND MD FRCPC, ALAN BR THOMSON MD PhD FRCPC FACP FRS FACG, \\ GUY TREMBLAY MD FRCPC BIM
}

IT BECK, DJ LEDDIN, SE LEMIRE, et al. Insurance rating of patients with inflammatory bowel disease: Report of a conference on morbidity and mortality. Can J Gastroenterol 1994;8(7):438-445. Patient members reported to the Crohn's and Colitis Foundation of Canada (CCFC) about their difficulties to obtain insurance. In 1991, the Lay Board of the CCFC requested its Medical Advisory Board (MAB) to investigate this problem. At that time, insurance ratings could be illustrated by the 1985 edition of Brackenridge's monograph on life risks. The MAB found that data on mortality were outdated. A conference on morbidity and mortality of inflammatory bowel disease (IBD) was organized by the authors and held in May 1992. Based on questionnaires to patients, evidence provided by invited speakers and the results of small group conferences, it was concluded that patients with IBD have difficulties in obtaining insurance, even though the quality of life and mortality of IBD patients is not very different from that of the general population. However, the mortality rate of the healthy insured population is lower than that of the general population, and thus much lower than that of IBD patients. Patients have a better chance to obtain insurance if there is a close cooperation between the treating physician and the medical officer of the insurance company. Changes have occurred since the conference held in May 1992. The recent edition of Brackenridge's text (1992) provides a better prognosis but unfortunately unchanged rating for patients with IBD than did the 1985 edition. Close cooperation between the Patient Advisory Committee of the CCFC and the Executives of the Canadian Life Insurance Medical Officers Association may further improve the insurance rating of patients with IBD. (Pour résumé, voir page 439)

Key Words: Canadian morbidity and mortality data, Crohn's and Colitis Foundation of Canada, Crohn's disease, Insurance rating, Lifestyle, Ulcerative colitis

Queen's University, Kingston, Ontario; Dalhousie University, Halifax, Nova Scotia; Université Laval, Quebec, Quebec; University of Calgary, Calgary, Alberta; University of Alberta, Edmonton, Alberta

Correspondence and reprints: Dr IT Beck, Division of Gastroenterology, Department of Medicine, Hotel Dieu Hospital, Queen's University, Kingston, Ontario K7L 5 G2

This paper was presented at the Basic Research and Clinical Implications in IBD meeting, April 6 to 9, 1994, held in Victoria, British Columbia. This paper has also been published in Sutherland LR, et al, eds. Inflammatory Bowel Disease: Basic Research, Clinical Implications and Trends in Therapy. Boston, Dordrecht and London: Kluwer Academic Publishers, 1994

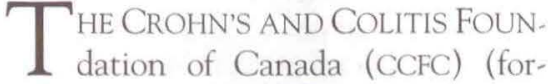
merly the Canadian Foundation for Ileitis and Colitis [CFIC]) supports medical research in inflammatory bowel disease (IBD), undertakes education of physicians and patients, and advocates support for some specific needs of patients with IBD. The Foundation has a Lay Board and a Medical Advisory Board (MAB). The Lay Board is involved in the administration of the Foundation and in organizing drives to obtain charitable donations. The MAB has three major committees: the $\mathrm{Re}$ search Committee, the Education Committee and the Patient Advocacy Committee. The Research Committee reviews research applications and advises the Lay Board on the distribution of funds to support research. The Education Committee provides educational material for patients and physicians.

Issues of concern to patients with IBD range from provincial funding of costly drugs and nutrients, the availability of insurance benefits for persons with IBD and the human rights of persons suffering from IBD. Because of this a Patient Advocacy Committee was established in 1986. This committee was charged to establish representations to provincial governments, to approach 


\section{Maladies inflammatoires de l'intestin et cote d'assurabilité : Rapport d'une conférence sur la morbidité et la mortalité}

RÉSUMÉ : Les patients membres de la Fondation canadienne des maladies inflammatoires de l'intestin (MII) ont déclaré éprouver des difficultés à s'assurer sur la vie. En 1991, les membres de la base de la Fondation canadienne des maladies inflammatoires de l'intestin ont demandé à son Conseil consultatif médical de se pencher sur ce problème. À ce moment, les cotes accordées par les compagnies d'assurances pouvaient être consultées dans l'édition 1985 du traité de Brackenridge des risques sur la vie. Le comité consultatif a découvert que les données sur la mortalité y étaient périmées. Une conférence sur la morbidité et la mortalité associées aux maladies inflammatoires de l'intestin a été organisée par les auteurs et a eu lieu en mai 1992. Sur la base des questionnaires distribués aux patients et des résultats présentés par les conférenciers invités, ainsi que des résultats tirés de conférences par petits groupes, il a été conclu que les patients atteints de MII ont de la difficulté à se faire assurer, même si leur qualité de vie et leur taux de mortalité ne sont pas très différents de ceux de la population en général. Le taux de mortalité de la population saine assurée est même plus faible que celui de la population en général et, de ce fait, beaucoup plus faible que celui des patients atteints de MII. Les patients ont une meilleure chance d'obtenir de l'assurance s'il y a une proche collaboration entre le médecin traitant et les autorités médicales des compagnies d'assurance. Des changements sont survenus depuis la conférence qui a eu lieu en mai 1992. La plus récente édition du Brackenridge (1992) offre une bien meilleure classification des patients atteints de MII, que celle de 1985. Une proche collaboration entre le comité consultatif des patients de la Fondation et l'Association des directeurs médicaux en assurance-vie pourrait améliorer davantage la cote d'assurabilité des patients atteints de MII.

the insurance industry and to deal with other relevant issues. The first chairman of this committee was Dr Edward Prokipchuk. During his chairmanship, the committee secured inclusion of total parenteral nutrition and some liquid nutrients in the drug lists of several provinces. At the September 20, 1991 meeting of the MAB, the second chair of this committee, Dr Suzanne Lemire, presented a report addressing the problems being faced by those with IBD seeking life insurance coverage. Examples of the current rating methods based on the 1985 edition of Brackenridge's (1) text on life risks suggested that there may be a great deficiency in the data upon which such rating is based, and thus it appeared that most of the data used were outdated.

A book written in 1985 could not have included morbidity and mortality data published after 1982. Any report published in 1982 would deal with cases that were collected during the 1970s. Because of the improved diagnostic techniques, improved medical and nutritional support, and safer and less complex surgery in the 1980 s, the MAB of the CCFC assumed that the mortality and morbidity figures must have improved since the publication of Brackenridge's text.

Therefore, the MAB of the CCFC organized a conference to review recent data on the morbidity and mortality of IBD. An Organizing Committee consisting of Drs Ivan T Beck (Chair), Kingston; Desmond J Leddin, Halifax; Suzanne E Lemire, Quebec; Eldon A Shaffer, Calgary; Lloyd R Sutherland, Calgary and Alan BR Thomson, Edmonton. The meeting was fully supported by the Lay Board, and $\mathrm{Mr}$ Raymond J van Berkel, then Executive Director of the CCFC from Toronto, was made an ex-officio member of the Organizing Committee. The Lay Board was also represented at the Conference by Dr Ted Hannah, Liaison Chairman of the Lay Board to the MAB. The advice of Dr Guy Tremblay, Past-President, Canadian Life Insurance Medical Officers Association, was obtained on the first meeting of this Committee.

Because the CCFC is a charitable or- ganization, there were limited funds available to arrange this meeting. Therefore, the organizing committee decided to hold the conference in combination with a major symposium on IBD. This allowed the committee to draw on the expertise of some of the well known international investigators who attended the other meeting. Starting with a reception on the evening of May 20, 1992, a symposium on 'Trends in inflammatory bowel disease therapy' was held in Quebec City between the May 21 and 23. The CCFC was fortunate to be able to organize its conference on morbidity and mortality during the day of May 20. The meeting attracted Drs Richard Farmer (previously from the Cleveland Clinic, presently the Medical Advisor to the Agency of International Development, Washington, DC, United States), Göran Hellers (from the Department of Surgery, Karolinska Institute, Huddinge University Hospital, Huddinge, Sweden) and Vibeke Binder (from the Medical Gastroenterology Department of Herlev Hospital, University of Copenhagen, Herlev, Denmark). In addition to these speakers, the committee was fortunate to have Rod Riley from the Canadian Centre for Health Information, Statistics Canada, talk on Canadian experience on morbidity and mortality of Crohn's disease and ulcerative colitis. Most importantly an outstanding clinician with in-depth knowledge of insurance matters who could interact with the speakers and the audience had to be found. Dr Tremblay, an academic cardiologist and a Past-President of the Canadian Life Insurance Medical Officers Association joined us at the first organizational meeting. He was extremely helpful, not only as a speaker during the conference, but also by giving advice as to what questions should be addressed and discussed in detail.

In addition to the speakers, 19 Canadian gastroenterologists and surgeons were invited to participate in the conference. The total number of participants was 30 . The invited guests represented a broad spectrum of individuals with specific interests. There was a good scattering of age and of geo- 
TABLE 1

\section{Program of the meeting}

\begin{tabular}{|c|c|}
\hline Part one & Chair \\
\hline Welcome & S Lemire \\
\hline Objective of conference & IT Beck \\
\hline $\begin{array}{l}\text { Results of patients' survey questionnaire on } \\
\text { insurance }\end{array}$ & LR Sutherland \\
\hline $\begin{array}{l}\text { Process by which life insurance applications } \\
\text { are rated }\end{array}$ & G Tremblay \\
\hline $\begin{array}{l}\text { The human cost of inflammatory bowel } \\
\text { disease }\end{array}$ & RG Farmer \\
\hline $\begin{array}{l}\text { Crohn's disease and ulcerative colitis - } \\
\text { Morbidity and mortality: the Canadian } \\
\text { experience }\end{array}$ & R Riley \\
\hline Morbidity and mortality in Crohn's disease & GHellers \\
\hline $\begin{array}{l}\text { Overview of morbidity and mortality in } \\
\text { ulcerative colitis }\end{array}$ & V Binder \\
\hline \multicolumn{2}{|l|}{ Panel discussion } \\
\hline Part two - Report on group discussions & Summarizer \\
\hline Ulcerative colitis & DJ Leddin \\
\hline Crohn's disease before surgery & LR Sutherland \\
\hline Crohn's disease after surgery & ABR Thomson \\
\hline Summary, conclusions and recommendations & IT Beck \\
\hline
\end{tabular}

TABLE 2

Discussion groups

\begin{tabular}{ll}
\hline Group I - Ulcerative colitis & Chair: Dr D Leddin \\
Participants: & \\
Dr V Binder & Dr CA Ottaway \\
Dr H Freeman & Dr R Preshaw \\
Dr J Irvine & Dr N Williams \\
Dr JWD McDonald &
\end{tabular}

Group II - Crohn's before surgery Chair: Dr L Sutherland Participants

$\begin{array}{ll}\text { Dr L DaCosta } & \text { DrF Martin } \\ \text { Dr D Daly } & \text { Mr R Riley } \\ \text { Dr R Farmer } & \text { Dr M Ste Marie } \\ \text { Dr B Feagan } & \text { Dr G Thompson }\end{array}$

Group III - Crohn's after surgery Participants

$\begin{array}{ll}\text { Dr JR Bourdages } & \text { Dr G Hellers } \\ \text { Dr W Depew } & \text { Dr RC Lapointe } \\ \text { Dr O Gagnon } & \text { Dr E Prokipchuk } \\ \text { Dr H Haddad } & \text { Dr J Sidorov }\end{array}$

graphic location. There was a mix of academic and nonacademic physicians and surgeons. Two of the invited practising gastroenterologists were also insurance medical officers.

The possibility of bias in the assessment of the Lay Board was considered by the Organizing Committee. It was possible that patients who encounter difficulties may call the CCFC and talk about the rejection of their application, but those who had no problems may never discuss the issue. Therefore, the Organizing Committee decided that before embarking on the conference it was necessary to ascertain whether the impression of the Lay Board of the CCFC was correct in assuming that patients with IBD have difficulties in obtaining insurance. Dr Sutherland was charged to obtain data on this and to report to the conference on his findings.

The conference on morbidity and mortality lasted one day; the program is listed in Table 1. In the morning lectures were given and in the afternoons small group sessions were held. The invited audience was divided into three small groups for discussion (Table 2). The groups reviewed designated specific subjects of IBD. Dr Leddin chaired and summarized the session on morbid- ity and mortality of ulcerative colitis, Dr Sutherland the session on Crohn's disease before surgery and Dr Thomson that on Crohn's disease after surgery. After the $2 \mathrm{~h}$ small group sessions, the summarizer reported to the plenary session for final discussion and conclusion. The recommendations of this meeting are based on the results of these discussions.

\section{SYNOPSIS OF THE LECTURES}

Results of patient's survey questionnaire on insurance: Dr Sutherland (2) reported that the database consisted of questionnaires filled out by patients of the Organizing Committee. As Toronto was not represented among the organizers, Dr Prokipchuk (of Toronto) was also asked to send out the questionnaires. Drs Beck, Leddin, Prokipchuk, Thomson and Sutherland sent questionnaires to 50 randomly selected patients under their care, while Dr Lemire, whose cases represented the experience of the French-Canadian population, sent questionnaires to 70 patients with IBD. Of the 320 questionnaires, 206 responded, providing a $66 \%$ response rate.

The results for straight life insurance indicate a high rejection rate for both diseases. For ulcerative colitis patients, the percentage acceptance without premium was only $31 \%$. Thirty-seven per cent were rated and $32 \%$ were rejected. For Crohn's disease patients, the acceptance, rating and rejection were $18 \%, 44 \%$ and $38 \%$, respectively. Rejection and special rating for disability insurance showed similar results. Interestingly, group life was refused in $35 \%$ of patients with ulcerative colitis and $17 \%$ of patients with Crohn's disease. During the discussion of his data, Dr Sutherland indicated that there was a possibility of selection bias. Patients who were rejected may have responded more readily than those who had obtained insurance without difficulty. On the other hand, patients who were well and would have obtained insurance without rating may not have applied because they believed that they would be rejected. Another problem was that there were no controls. However, even without controls the rejection rate of patients with $I B D$ was higher than that of the normal population, in whom straight life insurance is refused to only about $5 \%$ of applicants (3).

Considering all the shortcomings of a one-time mail questionnaire, this study provides reasonable evidence that patients with IBD have considerable difficulties in obtaining insurance. 
Process by which life insurance applications are evaluated/rated: Dr Tremblay (3) explained how insurance companies work. He pointed out that because individuals who have recognizable diseases have already been excluded when they applied for life insurance, the life expectancy of the insured population is half to a third better than that of the general population. This difference is obvious up to the first seven to eight years but persists for 15 years after obtaining insurance.

Dr Tremblay pointed out that the insurance business is competitive and companies want to sell insurance. For this reason, the medical director is responsible for the updating of the company's selection procedure. Similar to that of other specialists, the medical director attends many continuing medical education meetings. Many medical directors are in clinical academic practice and apply their knowledge to the insurance screening and rating of applications. Therefore patients with IBD may have a better chance to obtain insurance at a lower additional rate if they shop around at several insurance companies. Furthermore, the insurability of patients improves after periods of good health and, therefore, patients should be encouraged to reapply after periods of remission.

Most importantly, patients will do better in securing life insurance if their physician helps the medical director to evaluate the risk. Dr Tremblay advised that clinicians should write a letter, rather than just fill out a form, and if applicable, the treating physician should mention the period of remission, and that the patient is reliable, is not disabled from working and is under ongoing follow-up. Medications used should be mentioned, especially if the patient is not on steroids or immunosuppressive agents. Dr Tremblay suggested that patients who have group insurance coverage at their work should be advised not to change their jobs as they may lose their group insurance by moving to another company. Furthermore, to obtain individual insurance, an important factor is the patient's ability to function and ability to maintain the same job.

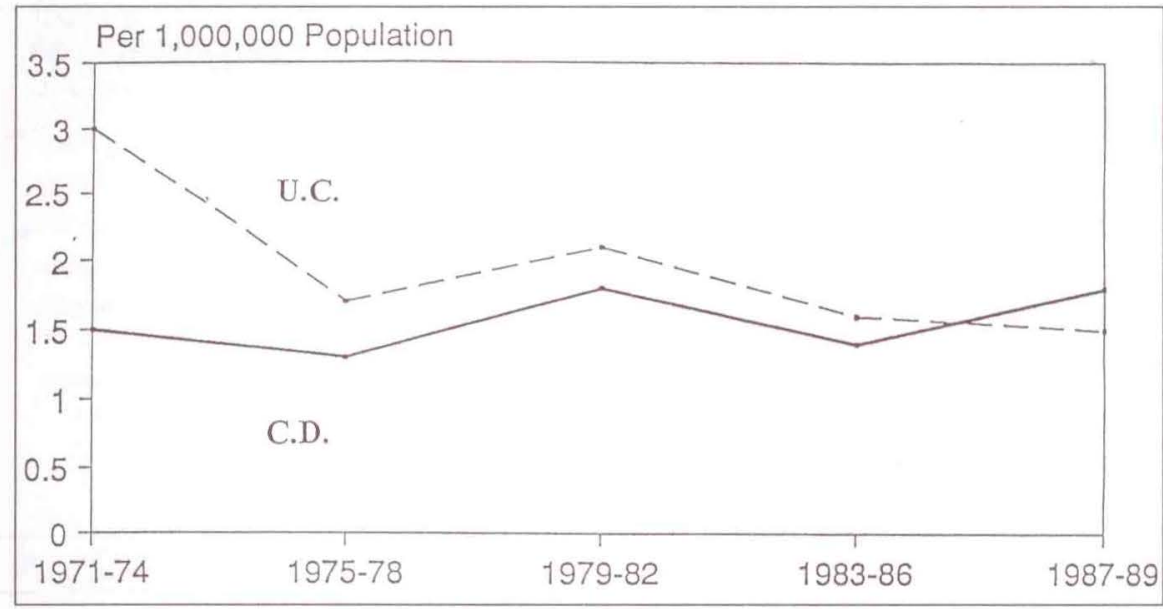

Figure 1) Changes in Canadian mortality rates of inflammatory bowel disease patients between 1971 and 1989. CD Crohn's disease; UC Ulcerative colitis. Reproduced with permission from reference 5

TABLE 3

Inflammatory bowel disease: ratio of discharges to deaths in Canadian hospitals

\begin{tabular}{lrrrrr}
\hline & $<24$ & $\mathbf{2 5 - 4 4}$ & $\mathbf{4 5 - 6 4}$ & $\mathbf{6 5 +}$ & Total \\
\hline $\begin{array}{l}\text { Crohn's disease } \\
1971-74\end{array}$ & 166 & 152 & 34 & 18 & 76 \\
$1975-78$ & 287 & 337 & 69 & 18 & 123 \\
$1979-82$ & 1800 & 291 & 73 & 16 & 127 \\
$1983-86$ & 1068 & 953 & 92 & 23 & 191 \\
$1986-89$ & - & 623 & 105 & 19 & 172 \\
Ulcerative colitis & & & & & \\
$1971-74$ & 136 & 100 & 33 & 7 & 42 \\
$1975-78$ & 367 & 282 & 50 & 16 & 70 \\
$1979-82$ & 484 & 234 & 65 & 13 & 61 \\
$1983-86$ & 1042 & 384 & 92 & 17 & 83 \\
$1986-89$ & 2388 & 440 & 101 & 20 & 96 \\
\hline
\end{tabular}

$-=$ No deaths

Human cost of IBD: Dr Farmer (4) reported that 164 patients with IBD followed at the Cleveland Clinic were studied. Only those patients whose disease started around age 20 years and whose follow-up was over 10 years were included in the study. The questionnaire was designed to assess their ability to function; social and recreational activities; attitude towards life and health; and medical status. Questions on the ability to support themselves dealt with work and family support; those on social and recreational activities dealt with relationship to family, and sexual, social and recreational habits. Questions on attitude towards life and health assessed depression, optimism etc, while medi- cal questions dealt directly with symptoms, medication, surgery, etc.

Dr Farmer concluded that patients with ulcerative colitis have a better quality of life than those with Crohn's disease. The quality of life of patients with both diseases was better before than after surgery. Most IBD patients have a close to normal lifestyle, with $44 \%$ functioning well and being able to maintain a working capacity close to normal, and $50 \%$ functioning suboptimally (but most are still able to work). Only 6\% had severe disabling disease.

Crohn's disease and ulcerative colitis - the Canadian experience with morbidity and mortality data: R Riley (5) noted that mortality data were obtained 


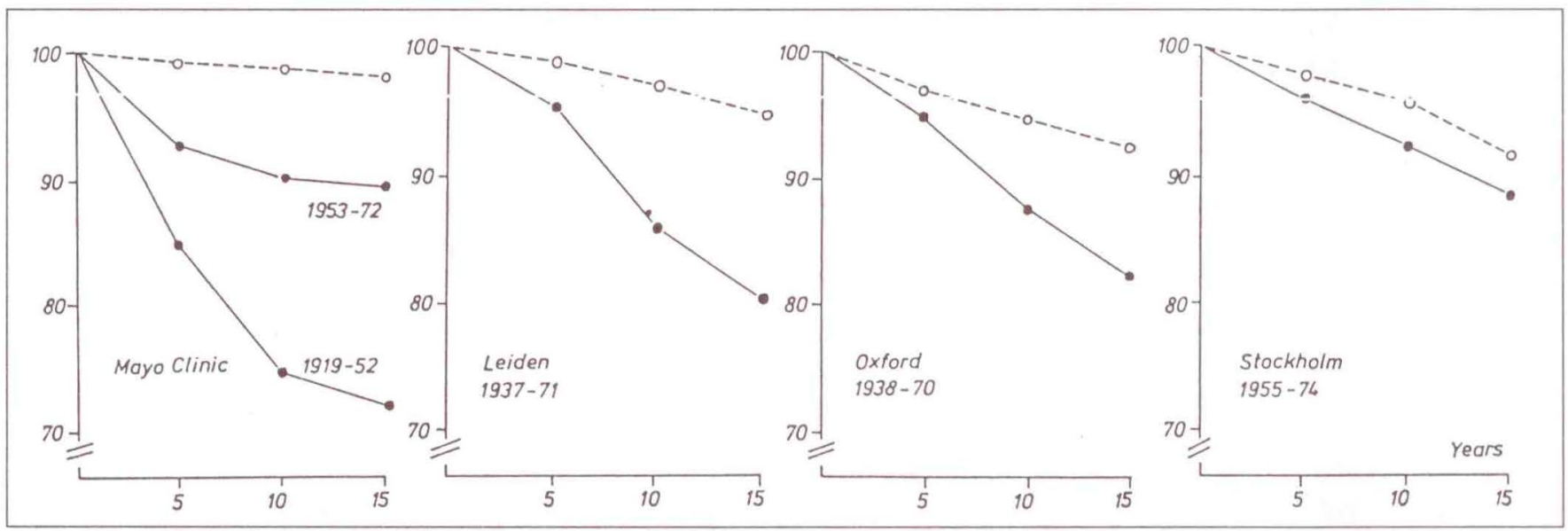

Figure 2) Expected (dashed line) and observed (continuous line) mortality from early studies on mortality in Crohn's disease. Studies, from left to right: The Mayo Clinic, Leiden, Oxford and Stockholm. Reproduced with permission from reference 7

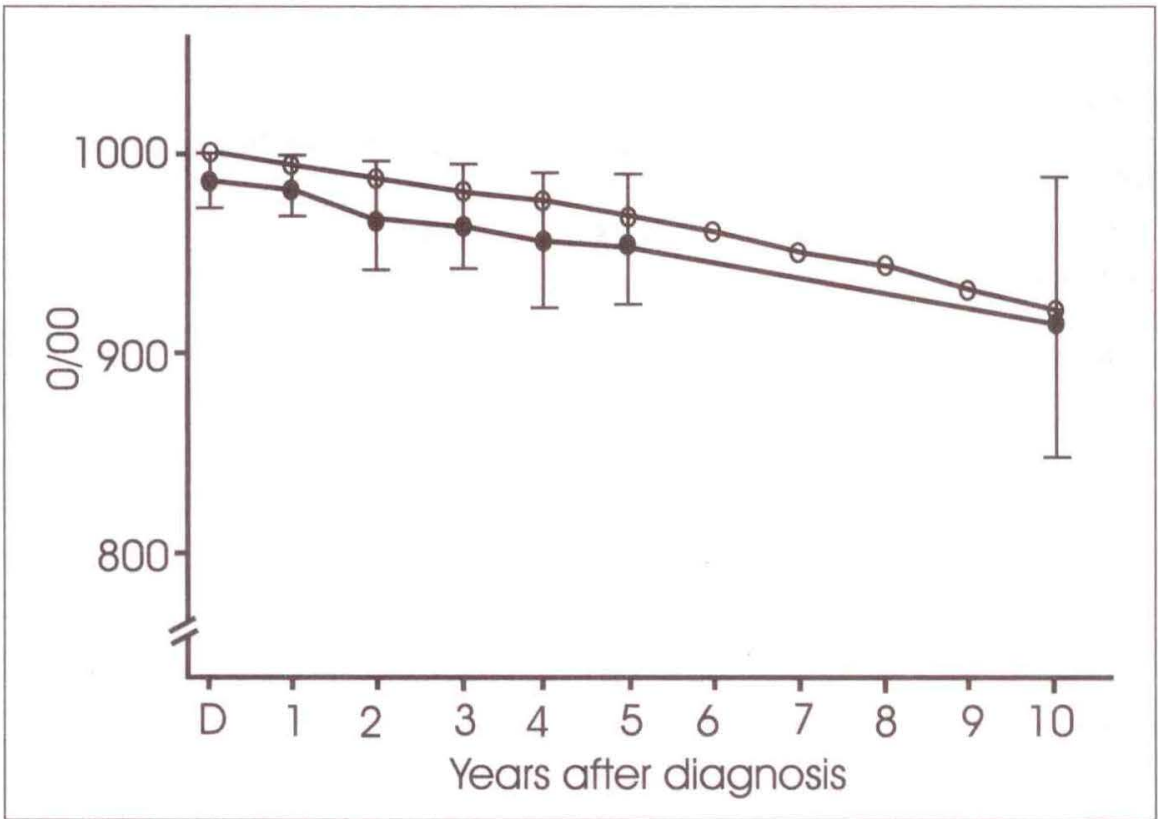

Figure 3) A later study on mortality in Crohn's disease: survival of patients with Crohn's disease (solid circles) compared with the age-and sex-matched background population (hollow circles). $D$ Diagnosis. SD bars represent \pm 2 SD. Reproduced with permission from reference 8

from hospital discharges between 1971 and 1989. In Canada, discharge diagnoses are filled out in every hospital. These forms are submitted to the Provincial Ministries of Health, which forwards them annually to the Canadian Centre for Health Information. As patients may be admitted several times a year, the discharge statistics collected at the Centre of Health, Information, Statistics Canada, do not provide data on incidence or prevalence. They are, however, useful to assess the general trends and provide accurate mortality statistics. In Canada similar to that in other western countries, Crohn's disease was on the rise. The discharges rose from 11.2/100,000 between 1971 and 1974 to $30.2 / 100,000$ between 1987 and 1989. The rate of discharge for ulcerative colitis remained unchanged in Canada (12.3/100,000 between 1971 and 1974 and 14.1/100,000 between 1987 and 1989).

For IBD as a whole, there is a greater increase in prevalence in the elderly. It is possible, however, that this increase in the elderly may be due to the inclu- sion of patients with ischemic bowel disease.

The mortality rate for IBD was steadily decreasing between 1971 and 1989 . Mortality due to ulcerative colitis was $1.5 /$ million and for Crohn's disease was 2/million (Figure 1). Mortality in the young was extremely low. The somewhat higher mortality in the elderly (Table 3) may be due to the fact that many of them have had multisystem diseases or may have suffered from ischemic bowel disease rather than from IBD.

Morbidity and mortality of Crohn's disease: Dr Hellers (6) pointed out that early studies on Crohn's disease indicate a higher mortality rate than that expected for the general population (Figure 2) (7). Later studies, for instance, by Dr Binder (8) which included patients up to 1985 , indicated that mortality for Crohn's disease was equal to that expected in non-IBD patients (Figure 3). Dr Hellers also reported on standard incidence ratio of cancer in Crohn's disease. In younger patients there is an increased excess mortality due to cancer. This is not the case in the older population where the cancer rate in the general population increases. After age 30 years, the ratio of cancer in Crohn's disease is 1.5 , similar to that in the general population.

Morbidity and mortality of ulcerative colitis: Dr Binder (9) gave an overview of morbidity and mortality in $1161 \mathrm{ul}$ cerative colitis patients seen in Copenhagen County, Denmark, between 
1962 and 1987. The median observation time was 11.7 years (range one to 25). There was a slight increase in mortality in the first year after diagnosis. However, once the patient survived the first year of illness, the mortality rate fell to that of the background population. The quality of life of patients with ulcerative colitis - regarding their working capacity, professional life, private, family and sexual adjustment - was similar to that of the general population. Cancer incidence was investigated on 600 patients who were followed for over seven years. The calculated lifetime cancer risk of ulcerative colitis $(3.6 \%)$ was not different from that in the Danish population (3.7\%).

\section{DISCUSSION GROUP REPORTS}

After these presentations, the conference broke up into three groups ( $\mathrm{Ta}$ ble 2). To update the statistical data, before the meeting participants of each group were requested to review the literature on morbidity and mortality of their designated area. Furthermore, the chairman of each group was instructed to outline with recommendations regarding the education of patients and physicians on the working of insurance companies. At the end of the group meetings, the chair of each session summarized the discussion and reported to the general session.

Ulcerative colitis (chaired by Dr Leddin): The ulcerative colitis group reviewed the appropriate section of Medical Selection of Life Risks by RDC Brackenridge (1). They agreed with the classification and the approach used in this volume to divide ulcerative colitis into mild, moderate and severe forms, but found that the mortality data were out of date. Several suggestions regarding the patient's and physician's approach to insurance companies were forwarded by this section and these are incorporated below with the recommendations of the two other groups.

Crohn's disease before surgery (chaired by Dr Sutherland): Dr Sutherland reported that since most patients eventually go to surgery, very little is known about the morbidity and mortal-

\section{TABLE 4}

\section{Recommendations of the conference to the Crohn's and Colitis Foundation} of Canada (CCFC)

The CCFC should develop an educational booklet for patients to:

-explain how insurance companies rate applicants

-encourage patients to reapply after having been in remission

-suggest that patients try to stay in the same job to maintain group insurance

-have regular follow-up because individuals under regular medical supervision are better rated

-develop a form with the information that is important to provide to insurance companies in order to obtain a more favourable rating - patients could take this form to their physician when requesting that the clinician write a letter to an insurance company

The CCFC should identify insurance brokers who have an understanding of inflammatory bowel disease

\section{TABLE 5}

\section{Recommendations of the conference to the Canadian Association of Gas-} troenterology

The Canadian Association of Gastroenterology should embark on an educational campaign to enlighten physicians about insurance companies and their ratings: specifically:

-clinicians should be encouraged to interact with insurance company physicians

-clinicians should be requested to write a letter about the patient's condition rather than just filling out a form

-if applicable, clinicians should point out that the patient has lost little time from work, has constant careful follow-up, is on maintenance therapy, has no jejunal disease, is not on total parenteral nutrition and/or is not on long term steroid therapy

-propose methods to investigate why jejunal disease is considered so deleterious that it excludes patients from insurance

ity of unoperated Crohn's disease. There are no predictors of whether a patient will require surgery. One members of the group, Dr Don Daly, a gastroenterologist and a medical officer of Prudential of England, provided for review $M \mathcal{E}^{\prime} \mathrm{G}$ Underwriting, which is used by his company for insurance rating. Patients whose Crohn's disease was localized solely to the small or to the large bowel paid lower premiums than those with ileocecal involvement. Patients with jejunitis were rejected irrespective of the severity of the disease. This astonished the group, which wondered whether jejunal Crohn's was confused with 'ulcerative jejunitis' which has more severe consequences than Crohn's disease involving the jejunum. The recommendations of this group will be discussed below.

Crohn's disease after surgery (chaired by Dr ABR Thomson): Surgical expertise in this group was provided by $\mathrm{Dr}$ Hellers. Due to the modern surgical and postsurgical techniques, morbidity and mortality of surgery in Crohn's disease has improved. Therefore, patients are sent to the operating room earlier and in better condition. Dr Hellers stated that taking the general risk of surgery as a basis, there is no additional surgical mortality related to Crohn's disease. Previous surgery does not increase the risk of a second or third operation. The reoperation rate is only $4 \%$ per year. Therefore, previous surgery should not be considered for extra rating for life insurance. However, previous surgery may be a factor in disability insurance. The recommendations of this session are discussed below in conjunction with those of the other two groups.

\section{RECOMMENDATIONS}

The composite recommendations of the three groups to the CCFC was that the Patient Advocacy Committee should develop educational material to explain to patients how insurance companies rate applicants. The pamphlet should emphasize that patients should 


\section{TABLE 6 \\ Rating of patients with ulcerative colitis}

\begin{tabular}{|c|c|}
\hline $\begin{array}{l}\text { Time since } \\
\text { diagnosis }\end{array}$ & Rating \\
\hline $\begin{array}{l}\text { Less than one } \\
\text { year }\end{array}$ & $\begin{array}{l}+100 \text { to }+250^{*} \text { and } 5 \\
\text { per mil for two years }\end{array}$ \\
\hline $\begin{array}{l}\text { One to two } \\
\text { years }\end{array}$ & $\begin{array}{l}+75 \text { to }+200^{*} \text { and } 2.5 \\
\text { per mil for one year }\end{array}$ \\
\hline After two years & +50 to $+150^{*}$ \\
\hline
\end{tabular}

Depending on the extent and severity of disease, frequency of relapses and quality of cancer surveillance. Additional rating of +50 for corticosteroid therapy (continuous or re peated). Normal expected mortality rate $=100$ : +100 Insured person pays twice the normal rate: +150 Insured person pays 1.5 times the normal rate; per mil Insured person pays times the number of units of currency per 1000 units of amount insured. Reproduced with permission from reference 10

reapply after a period of remission. To maintain group insurance, patients should try to stay in the same job because they may have difficulties in being accepted in a new group insurance plan. Patients should be told that they may get better insurance rating if they are regularly followed up. The CCFC should develop a form that provides information as to what physicians should convey to insurance companies in order to obtain a better rating for their patients, who could take this form to their physician as a guideline. Simultaneously, in the different communities, the CCFC should identify insurance brokers who have a better understanding of this disease (Table 4).

It was suggested that the Canadian Association of Gastroenterology should start an educational program to enlighten physicians about the methods of rating by insurance companies. Clinicians should learn to interact with the medical officers of insurance companies directly, and rather than filling out a form, they should write a detailed letter about their patients. If applicable, the patient's physician should indicate that he/she has constant careful follow-up, is compliant, is on maintenance therapy and does not require total parenteral nutrition or long term steroid or immunosuppressive therapy. They should indicate that the patient has lost little time from work. Because at least one underwriting text considered jejunitis a cause for complete

TABLE 7

\section{Rating of patients with Crohn's dis- ease}

\begin{tabular}{lc}
\hline $\begin{array}{l}\text { Time since } \\
\text { diagnosis }\end{array}$ & Rating \\
\hline $\begin{array}{l}\text { Less than one } \\
\text { year }\end{array}$ & +100 to $+250^{*}$ and 5 \\
$\begin{array}{ll}\text { Second year mil for } 3 \text { years } \\
+75 \text { to }+200^{*} \text { and } 2.5 \\
\text { per mil for } 2 \text { years }\end{array}$ \\
$\begin{array}{ll}\text { Thereafter } & +50 \text { to }+150^{*}\end{array}$
\end{tabular}

Depending on age at onset (worse for onset before age 20 years), severity of disease, frequency of relapses and evidence of complications. Additional rating of +50 for corticosteroid therapy (continuous or repeated). With surgery there is no additional rating but refer to insurance company's medical director if complex. Normal expected mortality rate $=100 ;+100$ Insured person pays twice the normal rate. +150 Insured person pays 7.5 times the normal rate: per mil Insured person pays times the num ber of units of currency per 1000 units of amount insured. Reproduced with permission from reference 10

rejection, the clinician should mention that the patient does not have jejunal disease. Furthermore, it would be of interest to find out from underwriting companies why jejunal disease should exclude Crohn's disease patients from insurance (Table 5).

\section{RECENT DEVELOPMENTS}

Several events occurred since the conclusion of this conference on morbidity and mortality. The third edition of Medical Selection of Life Risks was published in 1992 (10). This volume updated the literature on mortality of IBD and provided references up to 1991, which indicated that during the past year there was a decrease in mortality and that "long-term prognosis in both ulcerative colitis and Crohn's disease had significantly improved within the last decade and has become nearly similar in the two diseases". In spite of this, there was no considerable improvement in the ratings for ulcerative colitis (Table 6) and the ratings for Crohn's disease (Table 7) have not been improved.

A recent study of 140 patients with IBD and 100 controls carried out by Drs Leddin and co-workers (persônal communication) indicates that in the Halifax, Nova Scotia area, significantly more patients with IBD were refused life insurance $(17 \%)$ compared with controls $(7 \%)(\mathrm{P}=0.04)$. However, the ma- jority of IBD patients $(62 \%)$ were able to obtain life insurance, and this was not significantly different from that of the control population (73\%).

On the North American scene, excellent contacts were established with physicians specializing in insurance medicine. For instance, Dr Beck was asked to discuss ulcerative colitis and Crohn's disease in general and the results of the conference on IBD at the combined annual meeting of the American Academy of Life Insurance Medicine and the Canadian Life Insurance Medical Officers Association. Delegates were impressed by the approach taken towards the specialty of insurance medicine. A letter received from a member of the audience, Dr Daniel M Fleming, Vice-President and Chief Medical Director of North American Life Insurance Company states, "Once again, thank you for updating our understanding of this complex disorder. Your educational campaign to include the insurance physicians will undoubtedly be successful in the long run. Knowledge based on risk selection results in competitive insurance offers to your patients and our policyholders". This response from colleagues in insurance medicine suggests that similar cooperation has to be maintained in the future. Hopefully the Patient Advocacy Committee of the CCFC will prepare its brochure based on the recommendations of the conference on morbidity and mortality, and it may be advisable to prepare these brochures in cooperation with members of the executive of the Canadian Life Insurance Medical Officers Association.

\section{CONCLUSIONS}

Patients with IBD have considerable difficulty in obtaining straight life and disability insurance. This is in spite of the fact that the quality of life of most patients with IBD is not very different from that in the general population, and the mortality rate of IBD patients is decreasing and presently is not different from that of the general population. However, members of the conference learned from representatives of the insurance industry that the mortality rate of the general population is higher dur- 
ing the first 15 years than that of an insured population. Members of the conference learned that patients with IBD had a better chance to obtain insurance if there is close cooperation between the treating physician and the medical officer of the insurance company. Some changes have occurred

\section{REFERENCES}

1. Brackenridge RDC. Medical Selection of Life Risks, A Comprehensive Guide to Life Expectancy for Underwriters and Clinicians. New York: HL Press, 1985.

2. Sutherland LR. Results of patient's survey on insurability. Can J Gastroenterol 1994;8:129-31.

3. Tremblay G. Process by which life insurance applications are evaluated/rated. Can J Gastroenterol 1994;8:135-9.

4. Farmer RG. Human cost of inflammatory bowel disease. Can J Gastroenterol 1994;8:140-4.

5. Riley R. Crohn's disease and ulcerative colitis - Morbidity and mortality, the since the conference on morbidity and mortality was held in May 1992. In comparison with the 1985 edition of Medical Selection of Life Risks by RDC Brackenridge, the recent third edition (1992) provides a better prognosis, but as yet basically unchanged ratings for patients with IBD. Excellent contacts

Canadian experience. Can J

Gastroenterol 1994;8:145-50.

6. Hellers G. Morbidity and mortality of Crohn's disease. Can J Gastroenterol 1994;8:151-4.

7. Hellers G. Crohn's disease in Stockholm county 1955-74. A study of epidemiology, results of surgical treatment and long term prognosis. Acta Chir Scand 1979;490(S):1-84.

8. Binder V, Hendriksen C, Kreiner S. Prognosis in Crohn's disease - based on the results from a regional patient group from the county of Copenhagen. Gut 1985;26:146-50.

9. Binder V. Overview of morbidity and mortality in ulcerative colitis. Can J Gastroenterol 1994;8:155-6. have been established with the Canadian Insurance Medical Officers, and further close cooperation of the Patient Advocacy Committee with the executive of the Canadian Life Insurance Medical Officers Association may further improve the insurance rating of IBD patients.

10. Brackenridge RDC, Elder JW. Medical Selection of Life Risks, 3rd edn. New York: Stockton Press, 1992.

11. Andrews HA, Lewis P, Allan RN. Mortality in Crohn's disease a clinical analysis. Q J Med 1989;71:399-405.

12. Weterman IT, Biemond I, Pena AS. Mortality and causes of death in Crohn's disease: review of 50 years' experience in Leiden University Hospital. Gut 1990;31:1387-90.

13. Hiwatashi N, Yamazaki H, Kimura M, et al. Clinical course and long-term prognosis of Japanese patients with ulcerative colitis. Gastroenterol Jpn 1991;26:312-8. 


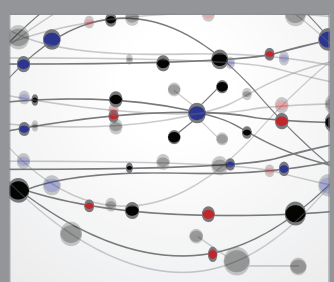

The Scientific World Journal
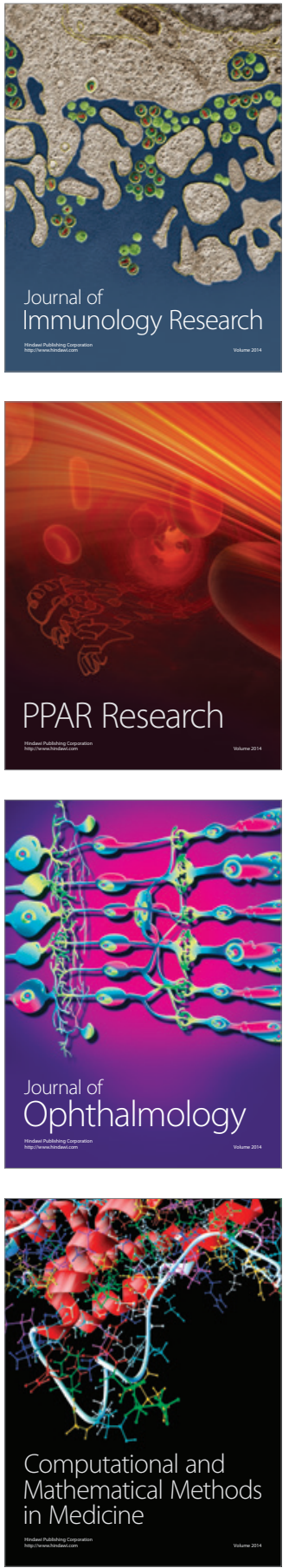

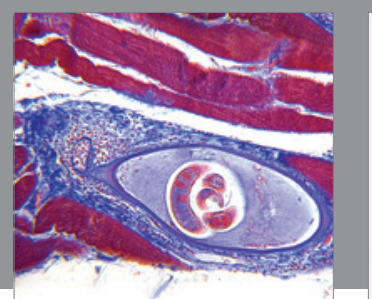

Gastroenterology Research and Practice

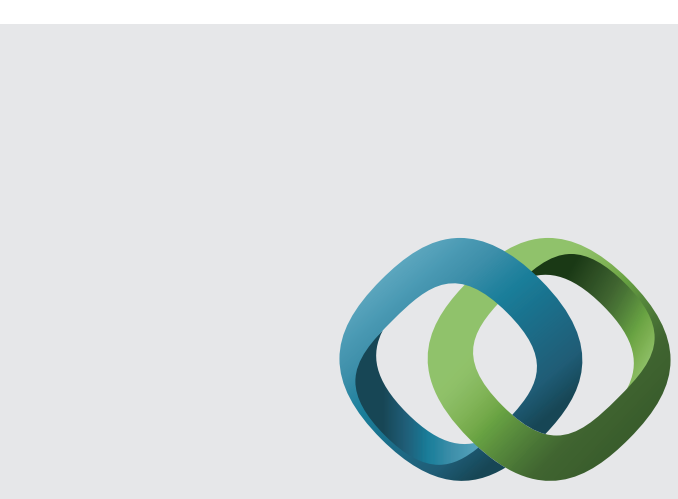

\section{Hindawi}

Submit your manuscripts at

http://www.hindawi.com
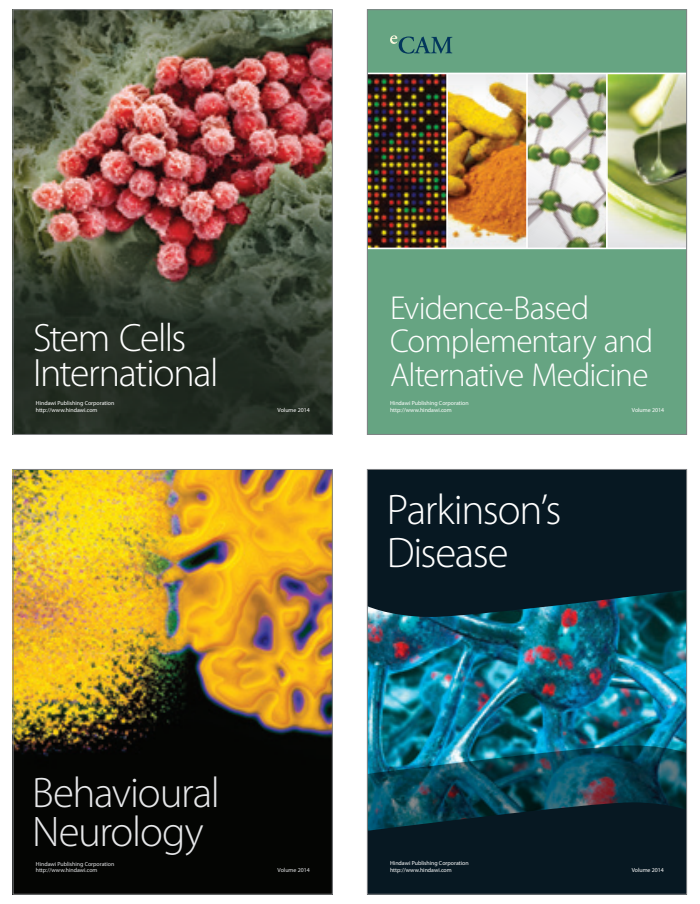
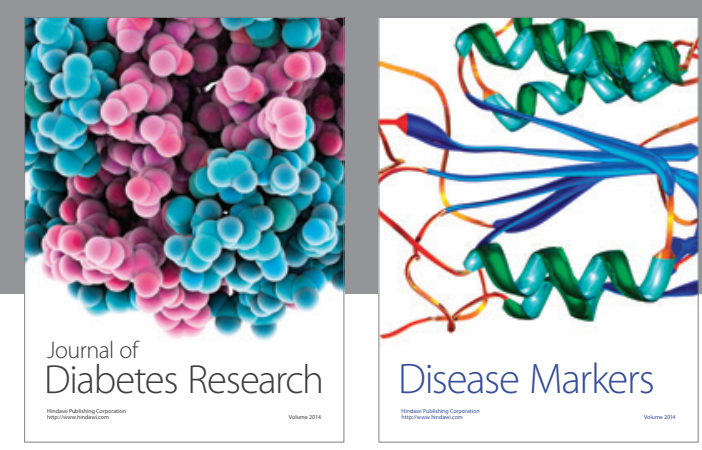

Disease Markers
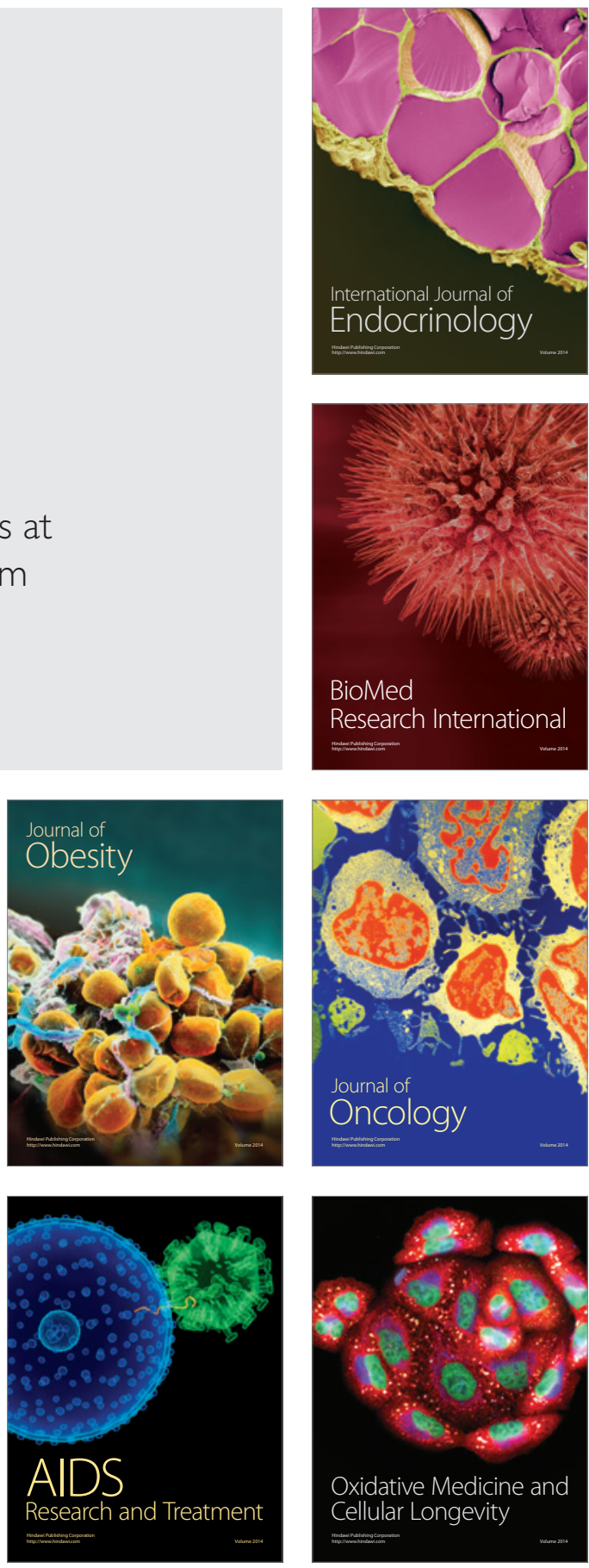